\title{
Myalgia with the presence of pathologic EMG correlates with perimysial inflammatory infiltrates
}

Kirsten Johannssen, MD, Nicholas Schwab, PhD, Carsten P. Wessig, MD, Karlheinz Reiners, MD, Heinz Wiendl, MD, and Claudia Sommer, MD

Neurol Neuroimmunol Neuroinflamm 2019;6:e549. doi:10.1212/NXI.0000000000000549

\section{Abstract}

\section{Objective}

We aimed to define normal numbers of inflammatory cells in muscle biopsies and to identify the predictive value of isolated muscle pain and increased creatine kinase regarding the diagnosis of myositis.

\section{Methods}

We analyzed muscle biopsies of 71 patients using immunostains for $\mathrm{CD} 3^{+}, \mathrm{CD}^{+}, \mathrm{CD}^{+}$, $\mathrm{CD} 68^{+}$, major histocompatibility complex class I, perforin, and myeloid-related protein (MRP) 8. Patients were categorized as follows-group 1: myalgia without further clinical or laboratory abnormalities $(\mathrm{n}=24)$; group 2: asymptomatic elevation of creatine kinase (hyperCKemia, $\mathrm{n}=$ 26); group 3: myalgia and pathologic EMG findings $(n=9)$; and group 4: otherwise healthy controls who had malignant hyperthermia susceptibility testing $(n=12)$.

\section{Results}

In the normal muscle biopsy specimens from group 4, mean endomysial macrophage (CD68 ${ }^{+}$) density was $21.7 \pm 5.6 / \mathrm{mm}^{2}$, and perimysial density was $13.0 \pm 5.6 / \mathrm{mm}^{2}$. Numbers of T-lymphocytes $\left(\mathrm{CD}^{+}\right)$were $5 \pm 3.5$ endomysially and $2.2 \pm 3.9 / \mathrm{mm}^{2}$ perimysially. This was not different from groups 1 and 2. Only group 3 patients had increased mean numbers of perimysial macrophages $\left(24.1 \pm 6.3 / \mathrm{mm}^{2} ; p=0.0005\right), \mathrm{CD}^{+}\left(7.6 \pm 4.9 / \mathrm{mm}^{2} ; p=0.0056\right)$, and $\mathrm{CD}^{+} \mathrm{T}$-lymphocytes $\left(5.4 \pm 3.1 / \mathrm{mm}^{2} ; p=0.0008\right)$ and displayed the activation marker MRP8 in all cases. Although inflammatory cells were increased in the perimysium in group 3, histology did not fulfill the criteria for dermatomyositis, polymyositis, or inclusion body myositis.

\section{Conclusions}

Normal muscle contains a considerable number of macrophages and T-lymphocytes. Muscle biopsy is likely to detect inflammatory changes in patients with myalgia or hyperCKemia only if pathologic EMG findings are present.

\author{
Correspondence \\ Dr. Sommer \\ sommer@uni-wuerzburg.de
}




\section{Glossary}

ATPase $=$ adenosine triphosphatase; $\mathrm{H} \& \mathrm{E}=$ hematoxylin and eosin; hyperCKemia = elevation of serum creatine kinase; $\mathbf{M H}=$ malignant hyperthermia; $\mathbf{M H C}=$ major histocompatibility complex; $\mathbf{M R P}=$ myoloid-related protein .

Muscle pain is a common complaint in clinical practice. Sometimes, an underlying myopathy or myositis is suspected, and patients are referred to a specialized center for neuromuscular diagnostic workup. Similarly, patients with isolated elevation of serum creatine kinase (hyperCKemia) may be referred for diagnostic workup of myopathy or for malignant hyperthermia $(\mathrm{MH})$ susceptibility testing. ${ }^{1}$ If clinical examination and EMG findings are normal, making a diagnosis in these patients can be difficult, and muscle biopsy may be performed. After exclusion of metabolic or mitochondrial myopathy or muscular dystrophy, immunohistochemistry may identify inflammatory cells and thus possibly detect myositis. Although there are precise clinical and histologic criteria for the diagnosis of polymyositis, dermatomyositis, and inclusion body myositis, ${ }^{2}$ sometimes, inflammatory infiltrates are found in muscle biopsies, which do not fulfill either of these criteria. Some of these may be diagnosed as "interstitial myositis," in particular, in the context of collagenoses. ${ }^{3,4}$ So far, normal limits for the presence of lymphocytes and macrophages in muscle serving to establish inflammation in a muscle biopsy still need to be defined. Our study therefore aimed at (1) determining the numbers of $\mathrm{T}$ cells and macrophages in normal muscle and (2) evaluating the frequency of myositis in patients with isolated muscle pain or hyperCKemia. In particular, we used markers for T-cell and macrophage subtypes, with the hypothesis that subtype profiles might be different between groups.

\section{Methods}

\section{Standard protocol approvals and patient consents}

Patients were recruited retrospectively from our histology database. All patients who had a muscle biopsy for diagnostic reasons between 1996 and 2006 were eligible $(n=1,065)$. Tissue sampling and analysis was approved by the Ethics Committee of the Würzburg Medical Faculty. Written informed consent was obtained from all participants.

\section{Patients}

Inclusion criteria for the study were as follows: (1) myalgia without further clinical or laboratory abnormalities, (2) asymptomatic hyperCKemia, (3) myalgia with and without hyperCKemia and pathologic findings in EMG, and (4) asymptomatic (negative testing for MH susceptibility to the University Department of Anesthesiology). ${ }^{5}$ Exclusion criteria were the presence of pareses, any other diagnosis of myopathy by clinical and histologic examination (including histochemistry and immunohistochemistry for metabolic and hereditary disorders), positive genetic testing for myotonic dystrophy type 2 , a history of statin use, recent immunization into an affected muscle, and any laboratory abnormalities other than hyperCKemia that were possibly related to the complaints. We used biopsies from patients with definite polymyositis $(\mathrm{n}=4)$, dermatomyositis ( $\mathrm{n}$ $=5)$, and inclusion body myositis $(\mathrm{n}=4)$ as positive controls for histology. Diagnoses were based on published standard criteria. ${ }^{2}$ For each patient, the following clinical and laboratory data were considered: age, clinical symptoms, routine serum chemistry including CK levels, C-reactive protein, erythrocyte sedimentation rate, whole-blood and differential cell counts, serum electrolytes, renal and liver function tests, thyroid function tests, autoantibodies (all: antinuclear antibodies, anti-neutrophil cytoplasmic antibodies, rheumatoid factor, Anti-Sjögren'ssyndrome-related antigen A, Anti-Sjögren's-syndrome-related antigen B, and Jo-1; from 2000: signal recognition particle, Mi2 alpha and beta, PL-7, PL-12, and Ro-52, immunology laboratory of Universitätsklinikum Würzburg and Euroimmun, Lübeck, Germany), and EMG recording. None of the patients was treated with immunosuppressive drugs including corticosteroids or immunomodulators at the time of biopsy. None of the patients' medical history showed relevant comorbidities at the time of presentation, particularly no evidence of rheumatologic, infectious, metabolic, or endocrine disorders.

\section{EMG}

Concentric needle EMG of deltoid, biceps brachii, anterior tibial, and rectus femoris muscles was performed. EMG was classified as "myopathic" if amplitudes of motor unit potentials were abnormally low, duration was shorter than laboratory normal values, and recruitment of motor units was increased.

\section{Histology and immunohistochemistry}

Muscle biopsy specimens were obtained for diagnostic purposes with informed consent. Open muscle biopsies were taken from a muscle selected following clinical or EMG criteria under local anesthesia. To avoid EMG-associated artifacts in biopsy specimens, the contralateral limb was selected for biopsy. In $\mathrm{MH}$ testing, the vastus lateralis muscle was biopsied according to standard protocols for the in vitro contracture testing. ${ }^{6}$ Routine histology and histochemistry were performed, including the following stains on 10- $\mu \mathrm{m}$ cryosections: hematoxylin and eosin $(\mathrm{H} \& \mathrm{E})$, Elastica van Gieson, modified Gomori trichrome, succinate dehydrogenase, nicotinamide-adenine dinucleotide, adenosine triphosphatase (ATPase), periodic acid-Schiff, oil red, acid phosphatase, cytochrome oxidase, and myophosphorylase activity, as well as dystrophin, sarcoglycan, caveolin-3, and dysferlin immunohistochemistry. For immunohistochemistry, flash-frozen muscle biopsy specimens were cut into $10-\mu \mathrm{m}$ cryostat sections. Unspecific binding in acetone-fixed, air-dried sections was blocked for 30 minutes in $10 \%$ normal bovine serum, and sections were then incubated with primary antibodies (supplemental table 1, links.lww.com/NXI/A101) or 
corresponding nonimmune immunoglobulin $\mathrm{G}$ ( $\mathrm{IgG}$ ) isotype controls, diluted in $1 \%$ normal bovine serum at $4^{\circ} \mathrm{C}$ overnight. Thereafter, a biotinylated secondary antibody (anti-mouse IgG $[\mathrm{H}+\mathrm{L}]$, Vector Laboratories, Burlingame, CA) and avidinbiotin-horseradish peroxidase complex (DAKO, Hamburg, Germany) were applied before incubating and staining with diaminobenzidine- $\mathrm{HCl}$ and $\mathrm{H}_{2} \mathrm{O}_{2}$. The specificity was controlled by omission of the primary antibodies.

\section{Quantification of immunohistochemistry/ histochemistry}

The stained tissue sections were analyzed using an Olympus $\mathrm{BH} 2$ microscope by an observer blinded to the identity of the slides. Endo- and perimysial immunoreactivity was evaluated across 5 visual fields in a magnification of $\times 200$ in each biopsy specimen, including 1 visual field that contained a larger blood vessel. The total number of immunoreactive cells was counted in a prespecified area of interest $\left(1.25 \mathrm{~mm}^{2}\right)$ and expressed as number of cells $/ \mathrm{mm}^{2}$. Evaluation was performed for $\mathrm{CD} 8^{+}, \mathrm{CD}^{+}, \mathrm{CD}^{+}$, and $\mathrm{CD} 68^{+}$ cells separately in the endo- and perimysium as shown in figure 1. To compare the immunoreactivity for major histocompatibility complex (MHC) I, perforin, and myeloidrelated protein (MRP) 8 between the biopsy specimens, a semiquantitative grading system was introduced as follows: no expression, 0 ; infrequent and weak expression, 1;

Figure 1 Analysis of inflammatory cells in muscle biopsies

A

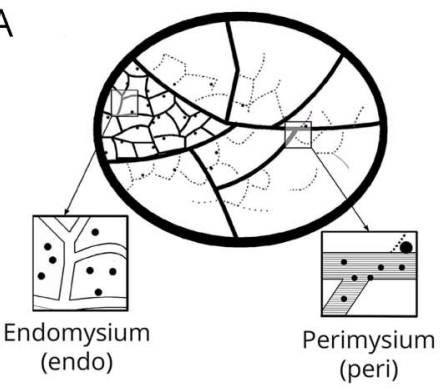

B. $\operatorname{CD} 3$ (endo)

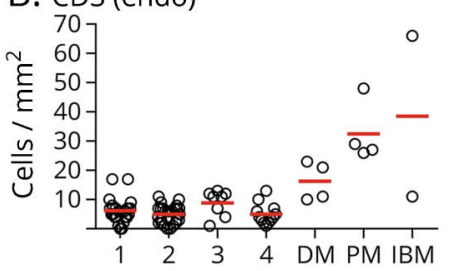

D. $\mathrm{CD} 4$ (endo)

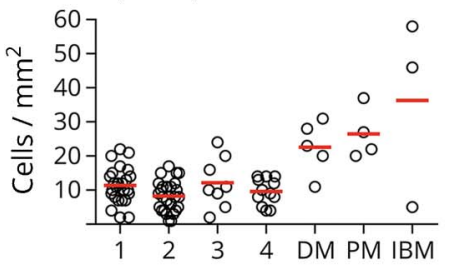

F. CD8 (endo)

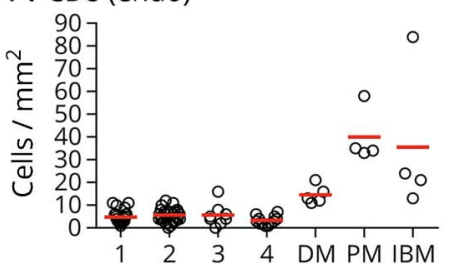

H. CD68 (endo)

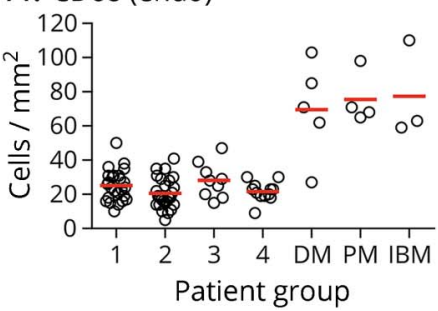

C. $\mathrm{CD} 3$ (peri)

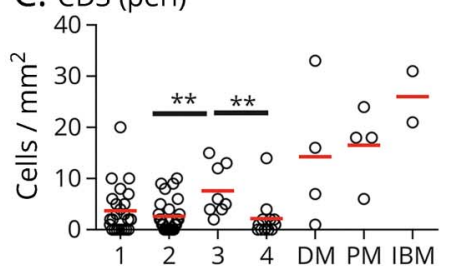

E. $C D 4$ (peri)

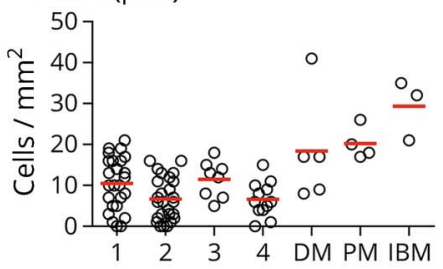

G. $\operatorname{CD} 8$ (peri)

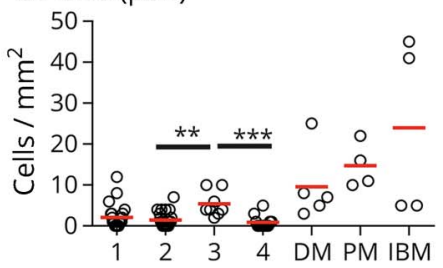

I. CD68 (peri)

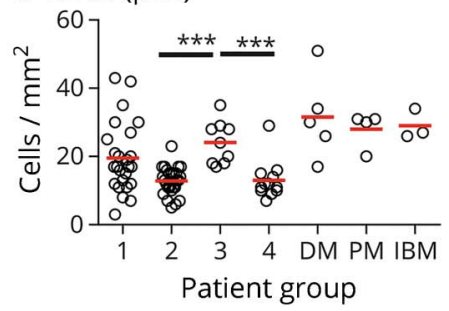

(A) Pattern of analysis with evaluation of endo- and perimysial immunoreactivity separately for each group (1-4) and positive controls (B-I) Dot blots showing the comparison of muscle biopsies from patients with myalgia only (group 1, $n=24$ ), hyperCKemia only (group 2, $n=26$ ), myalgia and pathologic EMG (group 3, $n=9$ ), and normal muscle biopsies from asymptomatic MH-negative patients (group $4, \mathrm{n}=12$ ) concerning the frequency of $\mathrm{CD}^{+}, \mathrm{CD}^{+}$, and $\mathrm{CD} 8^{+}$T-lymphocytes and of $\mathrm{CD}^{+} 8^{+}$macrophages (immunoreactive cells $/ \mathrm{mm}^{2}$ ). Biopsies of patients with dermatomyositis (DM) $(n=5)$, polymyositis $(P M)(n=4)$, and inclusion body myositis (IBM) $(n=4)$ were used as positive controls. The central horizontal bars denote the median value. ${ }^{\star \star} p<0.01$; $* \star \star p p<$ 0.001 . DM = dermatomyositis; IBM = inclusion body myositis; $\mathrm{PM}=$ polymyositis. 
restricted and moderate expression, 2; and extensive and strong expression, 3 . The same grading was used for acid phosphatase stains.

\section{Statistical analysis}

For group comparison, a one-way analysis of variance without assuming Gaussian distribution (Kruskal-Wallis test) was used with post-tests in case of overall significance (Dunn multiple comparison as post-test). $p<0.05$ was considered statistically significant. ${ }^{*}$ indicates $p<0.05,{ }^{* *}$ indicates $p<$ 0.01 and $^{* * *}$ indicates $p<0.001$. GraphPad Prism 5.0 software (San Diego, CA) was used for all calculations.

\section{Data availability}

The data that support the findings of this study are available upon request from the corresponding author, sommer@uniwuerzburg.de.

\section{Results}

\section{Patients}

Of 1,065 patients with muscle biopsies between 1996 and 2006, 76 met our inclusion criteria. Five cases had to be excluded because of evidence of rheumatologic and endocrine disorders that might be related to myalgia, which resulted in 71 cases for final analysis. Demographic and clinical data are presented in table 1 . We identified 24 cases in group 1 (myalgia only), 26 cases in group 2 (asymptomatic hyperCKemia), 9 cases in group 3 (myalgia and pathologic EMG), and 12 cases in group 4 (asymptomatic individuals who had $\mathrm{MH}$ susceptibility testing). In the whole sample, age at biopsy ranged from 6 to 72 years (mean 36.0 years). Muscles biopsied were vastus lateralis $(\mathrm{n}=53)$, deltoid $(n=9)$, gastrocnemius $(n=5)$, and biceps brachii $(n=4)$; no biopsy was taken from muscles previously examined by needle EMG.
Patients with myalgia (group $1, \mathrm{n}=24$ ) complained of pain at rest $(n=14)$ or pain during or after exercise $(n=10)$. The neurologic examination and CK levels and EMG were normal. The 26 patients composing group 2 had been referred because of persisting or recurrent asymptomatic hyperCKemia (range 300-20.000 IU/L, median 500 IU/L; laboratory upper limit of normal, $190 \mathrm{IU} / \mathrm{L})$. None of these patients was using drugs known to increase CK. All of them had normal clinical, laboratory, and EMG results. Group 3 consisted of 9 patients with myalgia and, contrary to group 1, pathologic EMG findings. Six patients had muscle pain at rest, 3 from pain during or after exercise. Six of the patients in group 3 had hyperCKemia (range 350-3,000 IU/L, median $700 \mathrm{IU} / \mathrm{L}$ ). EMG revealed a myopathic pattern in all 9 cases; 1 patient also had abnormal spontaneous activity in the form of positive sharp waves. Group 4 consisted of 12 patients who had been referred to the laboratory for $\mathrm{MH}$ susceptibility testing because of personal or family history of complications during anesthesia and who had normal CK levels and no signs or symptoms of muscle disease. All 12 patients were tested $\mathrm{MH}$ negative by an in vitro contracture test. None of them showed abnormalities in clinical, laboratory, and EMG features tested.

Patients with definite dermatomyositis $(n=5)$, polymyositis $(\mathrm{n}=4)$, and inclusion body myositis $(\mathrm{n}=4)$ were used as positive controls for histology. Their age ranged from 31 to 73 years. Eight patients had myalgia (62.0\%), and CK levels were increased in 5 cases (range between $400 \mathrm{U} / \mathrm{L}$ and 3,000 U/L). EMG was abnormal in all cases showing a myopathic pattern $11 / 13$ and abnormal spontaneous activity in the form of positive sharp waves in $3 / 13$.

\section{General pathology of the muscle specimens}

None of the biopsies from groups 1-4 provided evidence of endo- or perimysial pathology, unless specific stains for inflammatory cells (see table 2 ) were considered.

Table 1 Synopsis of patient data

\begin{tabular}{|c|c|c|c|c|c|c|c|c|}
\hline & \multirow{2}{*}{$\begin{array}{l}\text { Patients, } \\
\text { N }\end{array}$} & \multirow[b]{2}{*}{ M } & \multirow[b]{2}{*}{$\mathbf{F}$} & \multirow{2}{*}{$\begin{array}{l}\text { Age at biopsy } \\
\text { (range, mean) }\end{array}$} & \multicolumn{2}{|c|}{ Myalgia } & \multirow{2}{*}{$\begin{array}{l}\text { CK } \\
\text { elevated }\end{array}$} & \multirow{2}{*}{$\begin{array}{l}\text { EMG } \\
\text { abnormal }\end{array}$} \\
\hline & & & & & $\mathbf{R}$ & $\mathbf{E}$ & & \\
\hline Group 1-myalgia & 24 & 11 & 13 & $18-66(40.2)$ & 14 & 10 & 0 & 0 \\
\hline Group 2-asymptomatic hyperCKemia & 26 & 18 & 8 & $7-70(27.1)$ & 0 & 0 & 26 & 0 \\
\hline Group 3-myalgia and pathologic EMG & 9 & 6 & 3 & $19-67(45.8)$ & 6 & 3 & 6 & 9 \\
\hline Group 4-normal (MH testing negative) & 12 & 6 & 6 & $6-72(38.8)$ & 0 & 0 & 0 & 0 \\
\hline Total & 71 & 41 & 30 & $6-72(36.0)$ & 20 & 13 & 32 & 9 \\
\hline Positive controls & 13 & 2 & 11 & $31-73(60.8)$ & 6 & 2 & 7 & 13 \\
\hline DM & 5 & 1 & 4 & $63-73(68.6)$ & 3 & 1 & 2 & 5 \\
\hline PM & 4 & 1 & 3 & $31-67(46.3)$ & 3 & 0 & 2 & 4 \\
\hline IBM & 4 & 0 & 4 & $60-72(65.5)$ & 0 & 1 & 1 & 4 \\
\hline
\end{tabular}

Abbreviations: $\mathrm{CK}=$ creatine kinase; $\mathrm{DM}=$ dermatomyositis; IBM = inclusion body myositis; $\mathrm{MH}=$ malignant hyperthermia; $\mathrm{PM}=$ polymyositis; $\mathrm{R}=$ symptoms at rest, $\mathrm{E}=$ symptoms at exercise. 


\section{T-lymphocytes and macrophages in normal muscle}

The 12 biopsies from MH-negative patients without hyperCKemia (group 4) were histologically normal (H\&E stain, Trichrome-Gomori, and normal fiber type distribution in ATPase stains) and were used as normal controls. Immunohistochemistry for T cells revealed a mean of $5.0 \pm 3.5$ cells/ $\mathrm{mm}^{2} \mathrm{CD}^{+}$cells $/ \mathrm{mm}^{2}$ in the endomysium and of $2.2 \pm 3.9$ cells $/ \mathrm{mm}^{2}$ in the perimysium. We found a mean of $21.7 \pm 5.6 /$ $\mathrm{mm}^{2} \mathrm{CD} 68^{+}$macrophages in the endomysium, scattered between muscle fibers, and $13.0 \pm 5.6$ cells $/ \mathrm{mm}^{2}$ in the perineurium (table 2 and figure 1 ).

\section{Inflammatory cells in myalgia with pathologic EMG findings}

Patients with myalgia (group 1) did not show increased numbers of macrophages and T-lymphocytes compared with controls (group 4), neither did patients with asymptomatic hyperCKemia (group 2). In contrast, in biopsies of patients with myalgia and pathologic EMG findings (group 3), the number of perimysial macrophages was about double compared with controls $(p<0.01)$. Most macrophages were scattered between muscle fibers; small macrophage clusters were seen in 3/9 cases. Furthermore, group 3 showed 3 -fold increased numbers of perimysial $\mathrm{CD}^{+} \mathrm{T}$-lymphocytes compared with controls $(p<0.05$; table 2 and figure 1$)$.

\section{Subtyping of inflammatory cells}

Because total numbers of inflammatory cells did not differ between biopsies of controls and patients with isolated myalgia or asymptomatic hyperCKemia, we asked whether subtyping of T-lymphocytes and macrophages might differentiate between the groups. We therefore characterized T-lymphocytes by additional immunostaining $\left(\mathrm{CD}^{+}\right.$and $\left.\mathrm{CD}^{+}\right)$. The findings are shown in table 2 and figure 1 . In summary, only perimysial $\mathrm{CD} 8^{+} \mathrm{T}$-lymphocytes in muscle of patients with myalgia and pathologic EMG findings (group 3 ) were increased (6-fold, $p<0.01$ ) compared with controls (group 4). There was no difference in subtypes of T-lymphocytes between all other groups.

Expression of MRP8, a marker of activated macrophages, was weakly detected in 1 control (group 4; 8\%), in 8 of 24 patients with myalgia (group 1;33\%), and in 7 cases with asymptomatic hyperCKemia (group 2; 27\%). In contrast, all biopsies of patients with myalgia and positive EMG findings showed immunoreactivity for MRP8 $(n=9$; group 3$)$. Positive controls had moderate to high levels of MRP8 expression (table 3).

Acid phosphatase was strongly present in the positive controls, markedly present in endomysial cells of group 3, but only in single cells or not at all in groups 1,2, and 4 (data not shown). Because perforin has been identified as a mediator of CD8 cytotoxicity in inflammatory myopathies, ${ }^{7}$ we also used perforin immunohistochemistry in our samples. Perforin was not present in control patients (group 4), was present in 1 patient each in groups 1 and $2(4 \%)$, and in 3 cases with myalgia and positive EMG findings (group 3) (33\%), as well as in most of the positive controls (table 3 ).

Table 2 Numbers of T-lymphocytes and macrophages in muscle biopsies (results expressed as cells $/ \mathrm{mm}^{2}$ )

\begin{tabular}{|c|c|c|c|c|c|c|c|c|c|}
\hline & \multirow[b]{2}{*}{$\mathbf{N}$} & \multicolumn{2}{|l|}{$\mathrm{CD}^{+} 8^{+}$(SD) } & \multicolumn{2}{|l|}{$\mathrm{CD3}^{+}$(SD) } & \multicolumn{2}{|l|}{$\mathrm{CD4}^{+}$(SD) } & \multicolumn{2}{|l|}{$\mathrm{CD8}^{+}$(SD) } \\
\hline & & $\mathbf{E}$ & $\mathbf{P}$ & $\mathbf{E}$ & $\mathbf{P}$ & $\mathbf{E}$ & $\mathbf{P}$ & $\mathbf{E}$ & $\mathbf{P}$ \\
\hline Group 1 & 24 & $25.2(9.0)$ & $19.5(10.3)$ & $6.2(4.1)$ & $3.7(4.6)$ & $11.4(5.3)$ & $10.5(6.5)$ & $4.8(2.8)$ & $2.1(2.9)$ \\
\hline \multicolumn{10}{|l|}{ Myalgia } \\
\hline Group 2 & 26 & $20.6(9)$ & $12.8(4.1)$ & $5(3.1)$ & $2.7(3.2)$ & $8.3(4.5)$ & $6.7(5.2)$ & $5.6(2.9)$ & $1.4(1.8)$ \\
\hline \multicolumn{10}{|c|}{ Asymptomatic hyperCKemia } \\
\hline Group 3 & 9 & $28.2(10.3)$ & $24.11(6.3)$ & $8.9(4.4)$ & $7.6(4.9)$ & $12.1(7.4)$ & $11.5(4.4)$ & $5.6(4.8)$ & $5.4(3.0)$ \\
\hline \multicolumn{10}{|c|}{ Myalgia and pathologic EMG } \\
\hline Group 4 & 12 & $21.7(5.6)$ & $13.0(5.6)$ & $5.0(3.5)$ & $2.2(3.9)$ & $9.6(3.9)$ & $6.6(4.3)$ & $3.3(1.9)$ & $0.9(1.6)$ \\
\hline \multicolumn{10}{|c|}{ Normal (MH testing negative) } \\
\hline Positive controls & 13 & $58.8(18.2)$ & $23.8(6.8)$ & $21.8(14.2)$ & $14.0(8.4)$ & $22.4(4.3)$ & $17.4(8)$ & $25.5(23.1)$ & $12.5(17)$ \\
\hline DM & 5 & $55.7(22.7)$ & $25.3(10)$ & $13(5.4)$ & $11.4(11.2)$ & $18.6(7.1)$ & $14.7(10.7)$ & $11.7(3.23)$ & 7.7 (7.1) \\
\hline PM & 4 & $60.4(12.2)$ & $22.4(4.3)$ & $26(8.3)$ & $13.2(6)$ & $21.2(6.1)$ & $16.2(3.2)$ & $32(9.6)$ & $11.8(4.4)$ \\
\hline IBM & 4 & $61.9(22.7)$ & $23.2(3.5)$ & $30.8(31.1)$ & $20.8(5.7)$ & $29.1(22.2)$ & $23.5(5.9)$ & $28.4(26.1)$ & $19.2(17.6$ \\
\hline
\end{tabular}

Abbreviations: $\mathrm{DM}=$ dermatomyositis; $\mathrm{E}$ = endomysial; IBM = inclusion body myositis; $\mathrm{MH}$ = malignant hyperthermia; $\mathrm{N}=$ number of patients; $\mathrm{P}=$ perimysial; $\mathrm{PM}=$ polymyositis.

Given are the mean numbers $( \pm S D)$ of positive cells for the respective antibodies. 
Table 3 Differential immunohistochemistry of inflammatory cells

\begin{tabular}{|c|c|c|c|c|c|c|c|c|c|c|c|c|c|}
\hline & \multirow{2}{*}{$\begin{array}{l}\text { Patients, } \\
\text { N }\end{array}$} & \multicolumn{4}{|c|}{ MHC Class I (\%) } & \multicolumn{4}{|c|}{ Perforin (\%) } & \multicolumn{4}{|c|}{ MRP8 (\%) } \\
\hline & & 0 & 1 & 2 & 3 & 0 & 1 & 2 & 3 & 0 & 1 & 2 & 3 \\
\hline Group 1, myalgia & 24 & $24(100)$ & 0 & 0 & 0 & $23(96)$ & 1 & 0 & 0 & $16(67)$ & $8(33)$ & 0 & 0 \\
\hline $\begin{array}{l}\text { Group 2, asymptomatic } \\
\text { hyperCKemia }\end{array}$ & 26 & $26(100)$ & 0 & 0 & 0 & $25(96)$ & $1(4)$ & 0 & 0 & $19(73)$ & $7(27)$ & 0 & 0 \\
\hline $\begin{array}{l}\text { Group 3, myalgia and pathologic } \\
\text { EMG }\end{array}$ & 9 & $8(89)$ & $1(11)$ & 0 & 0 & $6(67)$ & $2(22)$ & $1(11)$ & 0 & 0 & $8(89)$ & $1(11)$ & 0 \\
\hline $\begin{array}{l}\text { Group 4, normal (MH testing } \\
\text { negative) }\end{array}$ & 12 & $12(100)$ & 0 & 0 & 0 & $12(100)$ & 0 & 0 & 0 & $11(92)$ & $1(8)$ & 0 & 0 \\
\hline DM & 5 & 0 & 1 & 3 & 1 & 1 & 1 & 3 & 1 & 0 & 0 & 3 & 2 \\
\hline PM & 4 & 0 & 1 & 2 & 1 & 1 & 0 & 3 & 0 & 0 & 0 & 3 & 1 \\
\hline IBM & 4 & 0 & 1 & 3 & 0 & 0 & 2 & 2 & 0 & 0 & 0 & 2 & 2 \\
\hline
\end{tabular}

Abbreviations: $\mathrm{DM}$ = dermatomyositis; IBM = inclusion body myositis; $\mathrm{MH}$ = malignant hyperthermia; $\mathrm{PM}$ = polymyositis.

Given are numbers of cases for each category (percentages in brackets). The strength of staining was rated according to the following scale: none, 0 ; infrequent and weak, 1; restricted and moderate, 2; and extensive and strong, 3. MRP8 = myeloid-related protein 8.

\section{MHC I immunoreactivity as an indicator of myositis}

MHC Class I molecules may be involved in initiating and maintaining the pathologic condition in myositis. ${ }^{8,9}$ Accordingly, in muscle tissue of the positive controls with inflammatory myopathies used as positive controls, most fibers and inflammatory cells expressed MHC I. In contrast, histologically, normal muscle fibers in group 4 did not express detectable levels of MHC I; as expected, only endothelial cells stained positively (figure 2). There was no MHC I expression in cases with myalgia (group 1) and cases with asymptomatic hyperCKemia (group 2). We could detect weak expression of MHC I only in 1 of 9 cases with myalgia and pathologic EMG findings (group 3, table 3). This was a 40-year-old man with myalgia during exercise for more than 10 years. He had no other pathologic findings in clinical and routine histologic results.

\section{Inflammatory cells in patients with myalgia and pathologic EMG}

Because group 3 with myalgia and pathologic EMG was the only subgroup with indicators of possible myositis, data of these patients will be summarized here. These patients were not different from the whole group regarding duration of disease, age, or sex. One patient had mild gynecomastia with normal hormonal blood levels, and 1 patient had wellcontrolled type 2 diabetes. Six of the 9 patients also had hyperCKemia. On a group level, there were increased perimysial macrophages $(p<0.01)$, perimysial $\mathrm{CD}^{+}$ T-lymphocytes $(p<0.05)$, and $\mathrm{CD}^{+}$T-lymphocytes $(p<$ $0.01)$ compared with controls. Small clusters of macrophages were found in 3/9 patients. Expression of MRP8 was detected in all 9 biopsies, perforin in only 3. MHC I expression was found in 1 biopsy only. Clinical data, therapy, and response to therapy for patients in group 3 are shown in supplemental table 2, links.lww.com/NXI/A100. Eight patients were treated with a trial course of corticosteroids. Of the 5 patients with follow-up data, 3 had a good and 1 a moderate response on myalgia within the next 6 months. One patient had arthritis 1 year later and was diagnosed with a mixed collagenosis, another patient developed interstitial lung disease 5 years later, and Jo-1 syndrome was diagnosed.

\section{Discussion}

Our study aimed at defining normal values for T-lymphocytes and macrophages in skeletal muscle. Based on these normal values, we investigated the frequency of myositis in patients with (1) isolated myalgia, (2) isolated hyperCKemia, and (3) with myalgia and pathologic EMG findings. In our cohort, numbers of T-lymphocytes and macrophages in patients with hyperCKemia or myalgia did not differ from normal controls. Importantly, normal muscle contains a considerable number of macrophages and T-lymphocytes. However, MHC I on muscle fibers, markers of macrophage activation (MRP8), or perforin expression by $\mathrm{T}$ cells are absent in normal muscle. Immunohistochemistry revealed an increased number of perimysial macrophages, $\mathrm{CD}^{+} \mathrm{T}$-lymphocytes, and $\mathrm{CD} 8^{+} \mathrm{T}$-lymphocytes only in the subgroup of patients with myalgia and pathologic EMG findings. This subgroup also had increased expression of MRP8, indicating recent immune activation, while most of the macrophages in the other subgroups can be considered inactive.

In our study, muscle biopsy detected inflammatory infiltrates in patients with myalgia if pathologic EMG findings were present, but not in patients with isolated myalgia or hyperCKemia. Similarly, definite muscle pathology was reported in only $2 \%$ of 240 patients who underwent muscle biopsy for evaluation of isolated myalgia. ${ }^{10}$ Others found an abnormal EMG in 2 of 180 patients with isolated myalgia, and muscle biopsy showed mild pathologic changes in only these $2 .{ }^{11}$ In contrast to this finding 
Figure 2 Expression of MHC Class I on muscle fibers

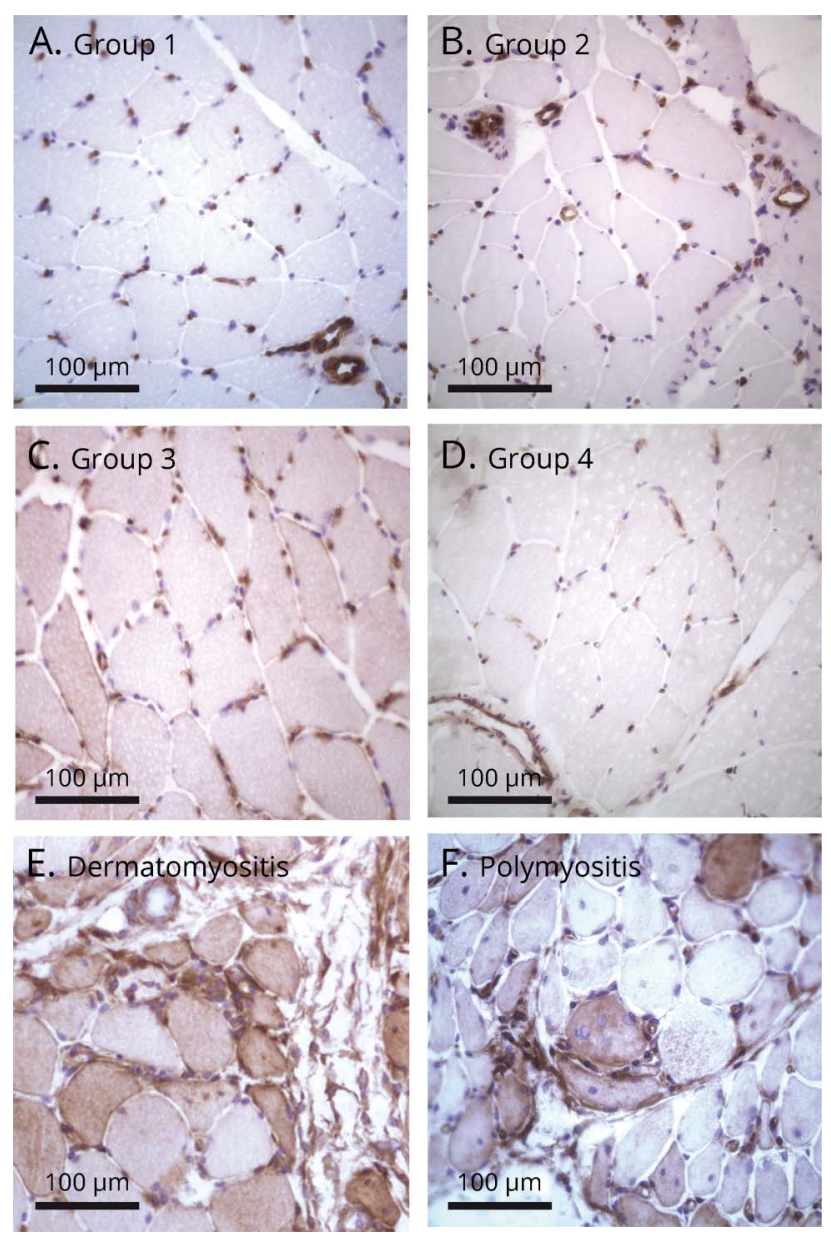

Typical specimens of patients with myalgia, group 1 (A), hyperCKemia, group 2 (B), myalgia and pathologic EMG, group 3 (C), and normal controls with negative malignant hyperthermia testing, group 4 (D). Brown staining demonstrates a positive expression of MHC Class I. In all specimens belonging to groups 1 (A), 2 (B), and 4 (D), muscle fibers did not stain for MHC Class I. Only capillaries were positive for MHC Class I as described earlier. ${ }^{18,19}$ In 1 of 9 cases with myalgia and pathologic EMG, weak MHC Class I expression could be detected (C). In the specimens of a patient with DM (E) and a patient with PM (F), positive MHC Class I staining was detected, as in most positive controls. $\mathrm{DM}=$ dermatomyositis; $\mathrm{MHC}=$ major histocompatibility complex.

and to our study, others found abnormal muscle biopsies in $55 \%$ of patients with asymptomatic or minimally symptomatic hyperCKemia, ${ }^{10}$ or even abnormal biopsy findings in $79 \%$ of their patients with myalgia and normal EMG. ${ }^{12}$ In 1 study, the authors were able to make a diagnosis from muscle biopsies in approximately one-third of 109 patients presenting with myalgia. ${ }^{13}$ Others, like our study, support a stronger positive predictive value of an abnormal EMG predicting an abnormal biopsy in up to $100 \% .{ }^{14}$ Of interest, these authors found an abnormal EMG in 14 of 19 patients with hyperCKemia, which is a higher ratio than in our study, in which none of the patients with isolated hyperCKemia had an abnormal EMG. Both extremes may be due to the small sample sizes.

CK levels increased by at least 5 to 10 times have been suggested to be predictive of a specific diagnosis by muscle biopsy, ${ }^{15,16}$ especially in patients younger than 24 years. Thus, 1 reason for the normal histologic findings in our patients with hyperCKemia may be the lower levels of CK elevation. Several studies found a relatively high amount of biopsies with the so-called heterogeneous nonspecific myopathic abnormalities such as increased fiber size variation, occasional cell necrosis, or abnormalities of the intermyofibrillar network. ${ }^{1,10,12,15}$ Apart from the study by Filosto et al., ${ }^{10}$ no other work investigated the expression of MRP8 and MHC I; therefore, weak inflammation in those slightly abnormal biopsies might not have been detected.

In the biopsies with an increase in inflammatory cells, these inflammatory changes were not sufficient to make a diagnosis of dermatomyositis, polymyositis, or inclusion body myositis according to standard criteria. ${ }^{2}$ Inflammatory cells were scattered in the endomysium; relevant parenchymal changes such as fiber necrosis, fiber atrophy, and perifascicular atrophy were not seen. This type of inflammatory process has been named interstitial myositis when described in the context of collagenoses, ${ }^{3}$ systemic vasculitis, ${ }^{17}$ or in focal myositis. ${ }^{11}$ In our cases showing this pattern, there was no evidence of collagenosis or other relevant comorbidities, and pathologically altered muscle fibers were completely missing. In particular, the absence of MHC I (observed in all but 1 case) indicates that the immunobiology of the muscle fibers appears to be normal. Whether this type of interstitial myositis represents an abortive form of a classical myositis syndrome or an entity of its own remains to be shown.

Our study has weaknesses inherent in its retrospective design. While histology, immunohistochemistry and their evaluation were performed in a strictly standardized way by a blinded investigator, this cannot be said for clinical investigation and EMG recordings, since the latter were taken from patients' charts. Furthermore, follow-up data are not available for most of the patients. In addition, the negative biopsy findings in some patients may be due to a sampling error. The response of myalgia to corticosteroids can be unspecific. Taking these caveats into account, our study allows the following conclusions: (1) T cells and macrophages are present in skeletal muscle under nonpathologic conditions but are not accompanied by indicators of immune cell activation or muscle fiber pathology/reactivity (especially MHC I). Thus, the mere appearance of immune cells in muscle biopsy specimens must not be overinterpreted. (2) Muscle biopsy is unlikely to detect a specific pathology in patients with (1) isolated myalgia or (2) isolated hyperCKemia or (3) the combination thereof, unless the EMG shows alterations suggestive of myopathy. Patients with myopathic EMG features and the histologic finding of interstitial myositis (perimysial macrophages, $\mathrm{T}$ cells, partly markers of activation) may benefit from immune therapy; yet, this will need to be studied in controlled trials.

\section{Author contributions}

K. Johannssen performed the histology and evaluations, compiled clinical data, and prepared the manuscript. N. 
Schwab performed data analyses and helped write the manuscript. C.P. Wessig acquired patient data and performed histologic evaluations. K. Reiners performed neurophysiologic measurements, acquired patient data, and revised the manuscript. H. Wiendl designed the study, analyzed data, and revised the manuscript. C. Sommer designed the study, acquired patient data, analyzed data, and revised the manuscript.

\section{Acknowledgment}

The authors thank H. Klüpfel (Department of Neurology, UKW) for technical support and M. Anetseder, MD, and F. Schuster, MD (Department of Anesthesiology, UKW), for performing malignant hyperthermia susceptibility testing.

\section{Study funding}

The study was supported by research funds of the University of Würzburg.

\section{Disclosure}

K. Johannssen reports no disclosures. N. Schwan received travel funding and/or speaker honoraria from Biogen and Novartis; holds a patent for usage of L-selectin as predictive marker for PML; and received research support from DFG, University Muenster, and PML Consortium. C.P. Wessig reports no disclosures. K. Reiners served on the scientific advisory boards of and received travel funding and/or speaker honoraria from Woerwag Pharma GmbH \& Co KG and Gesellschaft für Biofaktoren; served on the editorial board of Klinische Neurophysiologie; and holds stock in Bayer, Merck, MSD Sharp, Biogen, and Teva. H. Wiendl served on the scientific advisory boards of Bayer, Biogen, Sanofi Genzyme, Merck Serono, Novartis, Roche, and Teva; received travel funding and/or speaker honoraria from Bayer, Bayer Schering, Biogen, CSL Behring, EMD Serono, Fresenius Medical Caller, Sanofi Genzyme, Merck Serono, OmniaMed, Novartis, Teva, GlaxoSmithKline, and GW Pharmaceuticals; served on the editorial boards of PLoS One, Neurotherapeutics, Recent Patents on Inflammation \& Allergy Drug Discovery; consulted for Biogen, Merck Serono, Novartis, OmniaMed, Roche, and Sanofi Genzyme; and received research support from Bayer Healthcare, Bayer Vital, Biogen, Merck Serono, Novartis, Sanofi Genzyme, Sanofi US, Teva, German Ministry for Education and Research, Interdisciplinary Centre of Clinical Research, PML Consortium, German Research Foundation, Else Kroner Fresenius Foundation, Fresenius Foundation, Hertie Foundation, and RE Children's
Foundation. C. Sommer served on the scientific advisory boards of Air Liquide, Alnylam, Pfizer, Shire, and UCB; received travel funding and/or speaker honoraria from CSL Behring, Genzyme, Grifols, Kedrion, Pfizer, and Shire; served as associate editor of PAIN and PLoS One; and received research support from the German Research Foundation and CMT-Net. Disclosures available: Neurology.org/NN.

\section{Publication history}

Received by Neurology: Neuroimmunology \& Neuroinflammation July 2, 2017. Accepted in final form January 8, 2019.

\section{References}

1. Malandrini A, Orrico A, Gaudiano C, et al. Muscle biopsy and in vitro contracture test in subjects with idiopathic HyperCKemia. Anesthesiology 2008;109:625-628.

2. Dalakas MC. Inflammatory disorders of muscle: progress in polymyositis, dermatomyositis and inclusion body myositis. Curr Opin Neurol 2004;17:561-567.

3. Gruber-Wackernagel A, Scarpatetti M, Gruber MJ, Hermann J, Aberer E. Subacute cutaneous lupus erythematosus and interstitial myositis occurring with hepatitis B infection: response to antiviral therapy with Lamivudine. J Clin Rheumatol 2008;14 346-349.

4. Heuss D, Engelhardt A, Göbel H, Neundörfer B. Myopathological findings in interstitial myositis in type II polyendocrine autoimmune syndrome (Schmidt's syndrome). Neurol Res 1995;17:233-237.

5. Anetseder M, Hager M, Müller CR, Roewer N. Diagnosis of susceptibility to malignant hyperthermia by use of a metabolic test. Lancet 2002;359:1579-1580.

6. The European Malignant Hyperpyrexia Group. A protocol for the investigation of malignant hyperpyrexia (MH) susceptibility. Br J Anaesth 1984;56:1267-1269.

7. Goebels N, Michaelis D, Engelhardt M, et al. Differential expression of perforin in muscle-infiltrating T cells in polymyositis and dermatomyositis. J Clin Invest 1996;97: 2905-2910.

8. Englund P, Lindroos E, Nennesmo I, Klareskog L, Lundberg IE. Skeletal muscle fibers express major histocompatibility complex class II antigens independently of inflammatory infiltrates in inflammatory myopathies. Am J Pathol 2001;159:1263-1273.

9. Wiendl H, Hohlfeld R, Kieseier BC. Immunobiology of muscle: advances in understanding an immunological microenvironment. Trends Immunol 2005;26:373-380.

10. Filosto $\mathrm{M}$, Tonin $\mathrm{P}$, Vattemi G, et al. The role of muscle biopsy in investigating isolated muscle pain. Neurology 2007;68:181-186.

11. Echaniz-Laguna A, Chanson JB. Electromyography and muscle biopsy in chronic isolated Myalgia: a prospective study. Muscle Nerve 2016;54:321-324.

12. Dabby R, Sadeh M, Herman O, et al. Asymptomatic or minimally symptomatic hyperCKemia: histopathologic correlates. Isr Med Assoc J 2006;8:110-113.

13. Mills KR, Edwards RH. Investigative strategies for muscle pain. J Neurol Sci 1983;58: 73-78.

14. Joy JL, Oh SJ. Asymptomatic hyper-CK-emia: an electrophysiologic and histopath ologic study. Muscle Nerve 1989;12:206-209.

15. Prelle A, Tancredi L, Sciacco M, et al. Retrospective study of a large population of patients with asymptomatic or minimally symptomatic raised serum creatine kinase levels. J Neurol 2002;249:305-311.

16. Fernandez C, de Paula AM, Figarella-Branger D, et al. Diagnostic evaluation of clinically normal subjects with chronic hyperCKemia. Neurology 2006;66: 1585-1587.

17. Brunn A, Zornbach K, Hans VH, Haupt WF, Deckert M. Toll-like receptors promote inflammation in idiopathic inflammatory myopathies. J Neuropathol Exp Neurol 2012;71:855-867.

18. Karpati G, Pouliot Y, Carpenter S. Expression of immunoreactive major histocompatibility complex products in human skeletal muscles. Ann Neurol 1988; 23:64-72.

19. Emslie-Smith AM, Arahata K, Engel AG. Major histocompatibility complex class I antigen expression, immunolocalization of interferon subtypes, and $\mathrm{T}$ cell-mediated cytotoxicity in myopathies. Hum Pathol 1989;20:224-231. 


\title{
Neurology \\ Neuroimmunology \& Neuroinflammation
}

\author{
Myalgia with the presence of pathologic EMG correlates with perimysial inflammatory \\ infiltrates \\ Kirsten Johannssen, Nicholas Schwab, Carsten P. Wessig, et al. \\ Neurol Neuroimmunol Neuroinflamm 2019;6; \\ DOI 10.1212/NXI.0000000000000549
}

This information is current as of March 11, 2019

\begin{abstract}
Updated Information \&
Services

including high resolution figures, can be found at:

http://nn.neurology.org/content/6/3/e549.full.html

References

This article cites 19 articles, 0 of which you can access for free at: http://nn.neurology.org/content/6/3/e549.full.html\#\#ref-list-1

Citations

This article has been cited by 1 HighWire-hosted articles:

http://nn.neurology.org/content/6/3/e549.full.html\#\#otherarticles

Subspecialty Collections

This article, along with others on similar topics, appears in the following collection(s):

Autoimmune diseases

http://nn.neurology.org//cgi/collection/autoimmune_diseases

EMG

http://nn.neurology.org//cgi/collection/emg

Muscle disease

http://nn.neurology.org//cgi/collection/muscle_disease

Permissions \& Licensing

Information about reproducing this article in parts (figures,tables) or in its entirety can be found online at:

http://nn.neurology.org/misc/about.xhtml\#permissions

Reprints

Information about ordering reprints can be found online:

http://nn.neurology.org/misc/addir.xhtml\#reprintsus

Neurol Neuroimmunol Neuroinflamm is an official journal of the American Academy of Neurology.

Published since April 2014, it is an open-access, online-only, continuous publication journal. Copyright

Copyright $\odot 2019$ The Author(s). Published by Wolters Kluwer Health, Inc. on behalf of the American

Academy of Neurology.. All rights reserved. Online ISSN: 2332-7812.
\end{abstract}

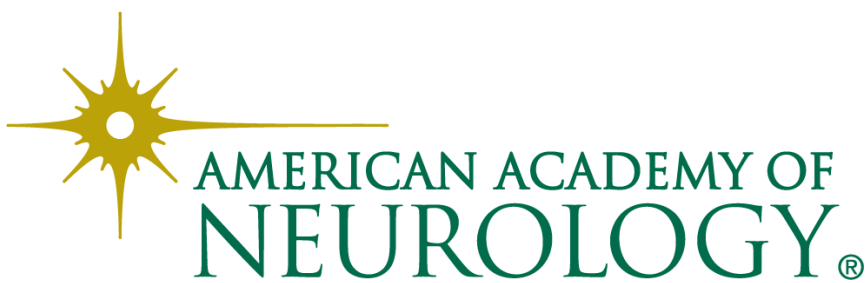

